\title{
INFLUÊNCIA DA ESTAÇÃO SOBRE AS PROTEÍNAS DO PLASMA SEMINAL NA RAÇA TABAPUÃ (BOS TAURUS INDICUS)
}

\author{
SEASON INFLUENCE ON THE SEMINAL PLASMA PROTEINS IN TABAPUA BREED \\ (BOS TAURUS INDICUS)
}

\author{
Chacur, M.G.M. ${ }^{1 *}$, Castillo, A.M.N. ${ }^{2}$, Godoy, G.B. ${ }^{2}$, Gandolfo, V.S. ${ }^{2}$, Machado Neto, N.B. ${ }^{2}$, \\ Kronka, S.N. ${ }^{2}$ e Guaberto, M.L. ${ }^{2}$
}

1 Departamento de Reprodução Animal. Faculdade de Ciências Agrárias. UNOESTE. Rod. Raposo Tavares, km 572. CEP 19067-175, Pres. Prudente-SP. Brasil. *chacur@unoeste.br ${ }^{2}$ UNOESTE. Universidade do Oeste Paulista. Pres. Prudente-SP. Brasil.

\section{PalaVRas chaVe adicionais \\ Touro Zebu. Época do ano. SDS-PAGE.}

\section{RESUMO}

O objetivo do estudo foi de avaliar a influência das estações do ano sobre as proteínas do plasma seminal na raça Tabapuã criados extensivamente. $O$ estudo foi realizado de junho a agosto (inverno) e de 2006 e de dezembro a fevereiro (verão) de 2007 em uma fazenda pertencente ao município de Presidente Prudente-SP, Brasil. Onze touros foram submetidos a seis coletas de sêmen por eletroejaculação em cada estação com intervalos de 14 dias. Amostras do sêmen foram centrifugadas a $1500 \mathrm{~g} / 15 \mathrm{~min}$ e acondicionadas em criotubos, estocadas a $-20^{\circ} \mathrm{C}$ até o processamento. As proteínas foram extraídas (Laemilli, 1970) e quantificadas (Bradford, 1976) e as eletroforeses realizadas; e os géis fixados e corados na mesma solução com $2 \%$ de Coomassie Blue R250. Em cinco touros a ausência de proteínas de alto peso molecular (APM $55 \mathrm{KDa}, 66 \mathrm{KDa}$ e $80 \mathrm{KDa}$ ) foi verificada no verão; e uma que se supõe ser de baixa fertilidade (BF $44 \mathrm{KDa}$ ) presente em dois touros no inverno. Sete touros mostraram presença de proteínas de APM ( $55 \mathrm{KDa}$ ) no inverno. Em três touros a proteína APM ( $55 \mathrm{KDa}$ ) e em um animal as proteínas APM (66 KDa e $80 \mathrm{KDa}$ ) estiveram presentes com uma condição satisfatória de sêmen. Oito touros mostraram presença de proteínas APM (125 KDa) no inverno e verão. Conclui-se que o inverno apresentou melhoria nos aspectos qualitativos do sêmen. Houve efeito sazonal entre a presença de proteínas específicas e a melhoria da qualidade do sêmen.

\section{AdDitionAl KEYWORDS}

Zebu bull. Season. SDS-PAGE.

\section{SUMMARY}

The objective of the present study was to evaluate the season influence on the seminal plasma proteins in Tabapua breed bulls raised on field. The study was conducted from June to August (winter) 2006 and from December to February (summer) 2007 in a farm in the country of Presidente Prudente, SP, Brazil. Eleven bulls were submitted to six semen collects throught eletroejaculation in each season at 14 days intervals. Samples of semen were centrifuged at $1500 \mathrm{~g} / 15 \mathrm{~min}$ and conditioned in criotubes and stored at $-20^{\circ} \mathrm{C}$ until further processing. The Proteins were extracted (Laemilli, 1970) and quantified (Bradford, 1976) and the electrophoresis was performed; the gels were fixed, and stained in the same solution with $2 \%$ of Coomassie Blue R250. In five bulls, the absence high molecular weight (HMW $55 \mathrm{KDa}, 66 \mathrm{KDa}$ and $80 \mathrm{KDa}$ ) proteins was verified in the summer and other one which is supposed to be of low fertility (LF $44 \mathrm{KDa}$ ), verified in two bulls in winter. Seven bulls showed presence of HMW (55KDa) in the winter. In three bulls HMW $(55 \mathrm{KDa}$ ) and in one animal HMW (66 $\mathrm{KDa}$ and $80 \mathrm{KDa}$ ) proteins were present with a satisfactory semen condition. Eight bulls showed presence of HMW proteins ( $125 \mathrm{KDa}$ ) in winter and summer. In conclusion, the winter period presented an improvement in the qualitative aspects of the semen. A seasonal effect between the presence of the specific proteins and the increase of the semen quality was observed. 


\section{INTRODUÇÃO}

Os perfis eletroforéticos das proteínas do plasma seminal auxiliam na avaliação clínica, em casos de infertilidade em touros (Gasset et al., 1997). Na década de 90, Killian et al. (1993) relataram a presença de quatro proteinas associadas com a fertilidade, dando início às pesquisas com proteínas do plasma seminal. Em reprodutores bovinos da raça Limousin, as estações do inverno e primavera influenciaram na presença de proteínas do plasma seminal com predomínio de proteínas de alto peso molecular: 55, 66 e $80 \mathrm{KDa}$, no verão o quadro espermático foi inferior nos touros com a presença da banda de $40 \mathrm{KDa}$ (Chacur et al., 2006). O presente estudo teve o objetivo de avaliar o efeito das estações do ano sobre as proteínas do plasma seminal, por meio da eletroforese SDS-PAGE em touros Tabapuã criados extensivamente.

\section{MATERIAL E MÉTODOS}

Foram utilizados 11 touros da raça Tabapuã Bos taurus indicus, com idade média de 30 meses, em repouso sexual, criados extensivamente no município de Presidente Prudente, SP -Brasil, sendo mantidos em pasto de Brachiaria decumbens, com sal mineral e água ad libitum. Doze colheitas de sêmen foram efetuadas em cada um dos 11 touros, pelo método da eletroejaculação, perfazendo 144 amostras analisadas, sendo seis colheitas no inverno e seis colheitas no verão, com intervalos de 14 dias entre as mesmas. As amostras foram centrifugadas a $1500 \mathrm{~g}$ por 15 minutos, estocando $1 \mathrm{ml}$ do plasma seminal em criotubos de $1,5 \mathrm{ml}$, devidamente identificados e armazenados a $-20^{\circ} \mathrm{C}$ para posterior realização das análises por meio da eletroforese SDS-PAGE, com extrações e quantificações das proteínas segundo Laemilli (1970) e Bradford (1976), respectivamente. As amostras foram colocadas em cuba eletroforética vertical ligada a corrente elétrica $(50 \mathrm{~V}$ x $50 \mathrm{~mA}$ por 30 minutos e $300 \mathrm{~V}$ x $16 \mathrm{~mA}$, de 4 a 6 horas). A revelação das bandas protéicas foi feita em solução a $2 \%$ de Coomassie blue R-250. O modelo matemático utilizado foi:

$$
x_{i j}=m+c_{i}+t_{j}+e_{i j}
$$

em que:

$\mathrm{x}_{\mathrm{ij}}$ : valor observado para a estação i no touro j;

$\mathrm{m}$ : média geral;

$c_{i}$ : efeito da estação i;

$\mathrm{t}$ : efeito do touro $\mathrm{j}$;

$\mathrm{e}_{\mathrm{ij}}$ : efeito do acaso.

O delineamento foi inteiramente ao acaso com o fator raça e estações climáticas (inverno e verão), os dados foram submetidos à análise de variância e posteriormente aplicou-se o teste de Tukey a 5\%, conforme Banzatto e Kronka (2006).

\section{RESULTADOSEDISCUSSÂO}

No verão ocorreu uma queda na qualidade espermática dos touros, quando comparada ao inverno. No verão, as percentagens inferiores de animais que revelaram a presença das bandas de $9 \mathrm{KDa}$ e $12 \mathrm{KDa}$ foram respectivamente de $72,72 \%$ e $45,45 \%$ (tabela I), podendo as percentagens superiores no inverno de $90,90 \%$ e $63,63 \%$ estar relacionadas com o vigor espermático significativamente maior encontrado nessa estação do ano, viabilizando um maior metabolismo espermático, o qual poderia aumentar a fertilidade desses annimais.

A proteína de $20 \mathrm{KDa}$ esteve presente em $27,27 \%$ das amostras nas duas estações do ano, inferior aos $100 \%$ relatado em reprodutores Limousin, nas mesmas estações do ano (Chacur et al., 2004; Chacur e Machado Neto, 2007). Provavelmente os touros zebuínos necessitem menos da proteína de $20 \mathrm{KDa}$, pois estão mais adaptados ao calor, quando comparados às raças européias. Houve incidência similar no inverno e inferior no verão para a proteína de $26 \mathrm{KDa}$ em relação a descrita por Chacur e Machado Neto (2007) em taurinos. Essa 
Tabela I. Percentagens de ocorrência de bandas protéicas específicas no plasma seminal de touros Tabapuã nas estações do inverno e verão. (Occurrence percentages of specific proteic bands in bulls seminal plasma in winter and summer seasons).

\begin{tabular}{lccccc}
\hline Touros & Proteínas $(\mathrm{KDa})$ & \multicolumn{2}{c}{ Inverno $(\mathrm{n}=11)$} & \multicolumn{2}{c}{ Verão $(\mathrm{n}=11)$} \\
\hline A, B, C, D, E, F, H, I, J, K, & 6 & $9 / 11$ & $(81,81 \%)$ & $10 / 11$ & $(90,90 \%)$ \\
A, B, C, D, E, F, G, H, J, K & 9 & $10 / 11$ & $(90,90 \%)$ & $8 / 11$ & $(72,72 \%)$ \\
D, E, F, H, I, J, K & 12 & $7 / 11$ & $(63,63 \%)$ & $5 / 11$ & $(45,45 \%)$ \\
A, B, C, D, E & 13 & $5 / 11$ & $(45,45 \%)$ & $1 / 11$ & $(9,09 \%)$ \\
A, B, C, E, F, G, J & 17 & $3 / 11$ & $(27,27 \%)$ & $7 / 11$ & $(63,63 \%$ \\
A, D, E, F, J & 20 & $3 / 11$ & $(27,27 \%)$ & $3 / 11$ & $(27,27 \%)$ \\
A, B, C, D, E, F, G, H, I, J, K & 26 & $6 / 11$ & $(54,54 \%)$ & $11 / 11$ & $(100 \%)$ \\
A, B, C, E, F, H, I, J, K & 35 & $4 / 11$ & $(36,36 \%)$ & $7 / 11$ & $(63,63 \%)$ \\
A, B, E, F, G, H, J, K & 44 & $2 / 11$ & $(18,18 \%)$ & $8 / 11$ & $(72,72 \%)$ \\
A, C, D, E, F, H, I, J & 55 & $7 / 11$ & $(63,63 \%)$ & $3 / 11$ & $(27,27 \%)$ \\
B, D, H, I, K & 66 & $2 / 11$ & $(18,18 \%)$ & $4 / 11$ & $(36,36 \%)$ \\
A, C, D, E, F, I, J, K & 75 & $6 / 11$ & $(54,54 \%)$ & $6 / 11$ & $(54,54 \%)$ \\
A, B, C, I & 80 & $1 / 11$ & $(9,09 \%)$ & $4 / 11$ & $(36,36 \%)$ \\
A, C, F, I, J & 105 & $4 / 11$ & $(36,36 \%)$ & $3 / 11$ & $(27,27 \%)$ \\
A, B, C, E, F, G, H, I, J, K & 125 & $9 / 11$ & $(81,81 \%)$ & $10 / 11$ & $(90,90 \%)$ \\
\hline
\end{tabular}

proteína tem sido alvo de estudos por conferir baixa fertilidade aos touros, quando presente no plasma seminal (Killian, 1999).

A banda protéica de $55 \mathrm{KDa}$, esteve ausente no inverno e presente em $44,44 \%$ dos touros Limousin no verão (Chacur et al., 2004; 2006). Observou-se no presente trabalho uma proteína de $66 \mathrm{KDa}$, identificada em dois touros (B e D) no inverno e em quatro animais (D, H, I e K) no verão. A literatura descreve essa banda e a denomina albumina (Killian, 1999).

Foi identificada uma proteína de $80 \mathrm{KDa}$, provavelmente a lactoferrina, encontrada comumente no plasma seminal de garanhões, agindo como antioxidante (Inagaki, 2002).

\section{BIBLIOGRAFIA}

Banzatto, D.A. e Kronka, S.N. 2006. Experimentação Agrícola. $4^{a}$ ed. FUNEP. Jaboticabal. $237 \mathrm{pp}$.

Bradford, M.M. 1976. A rapid and sensitive method for the quantitation of microgram quantities of protein utilizing the principle of protein-dye binding. Anal. Biochem., 72: 248-254.

Chacur, M.G.M., Machado Neto, N.B. and Rabes-
Essa proteína esteve presente em um touro $(9,09 \%)$ no inverno e em quatro animais $(36,36 \%)$ no verão. Observou-se uma banda de $105 \mathrm{KDa}$ em quatro touros $(36,36 \%)$ no inverno e em três $(27,27 \%)$ no verão, segundo Gatti et al. (1999) essa proteína colabora na motilidade espermática.

Novas investigações nas diferentes raças, faixas etárias e épocas do ano são necessárias para uma melhor compreensão dos fatores que levam à oscilação na presença das proteínas do plasma seminal na espécie bovina. Conclui-se que as estações de inverno e verão revelaram influência na composição e percentagem de bandas protéicas com pesos específicos.

quine, M.M. 2004. Season influence upon seminal plasma proteins in bulls. XV International Congress on Animal Reproduction. Vol. 1. 236 pp. Chacur, M.G.M., Machado Neto, N.B. and Cristancho, D.R. 2006. Winter-spring and summer influence upon seminal plasma proteins in bulls. Anim. Reprod., 3: 251.

Chacur, M.G.M. e Machado Neto, N.B. 2007. 
CHACUR, CASTILLO, GODOY, GANDOLFO, MACHADO NETO, KRONKAE GUABERTO

Influência da estação do ano sobre as proteínas do plasma seminal de touros Limousin. Veterinária Notícias, 13: 47-53.

Gasset, M., Saiz, J.L., Lainez, J., Sanz, L., Gentzel, M., Töpfer-Petersen, E. and Calvete, E.J. 1997. Conformational features and thermal stability of bovine seminal plasma protein PDC-109 oligomers and phosphorylcholine-bound complexes. Eur. J. Biochem., 250: 735-744.

Gatti, J.L., Druart, X., Guérin, Y., Dacheux, F. and Dacheux, J.J. 1999. Kilodalton protein in epididymal fluids of domestic mammals in angiotensin-I covering enzyme (ACE) evidence that sperm are the source of this ace. Biol.
Reprod., 60: 937-945.

Inagaki, M. 2002. Purification and quantification of lactoferrin in equine seminal plasma. J. Vet. Med. Sci., 64: 75-77.

Killian, G.J., Chapman, D.A. and Rogowski, L.A. 1993. Fertility-associated proteins in Holstein bull seminal plasma. Biol. Reprod., 49: 12021207.

Killian, G.J. 1999. The role of marker protein in reproductive efficiency. Vet. Sci. Extension, 29: 1112-1120.

Laemilli, U.K. 1970. Cleavage of structural proteins during assembly of the head of bacteriophage T4. Nature, 227: 680-685.

Archivos de zootecnia vol. 60, núm. 230, p. 304. 